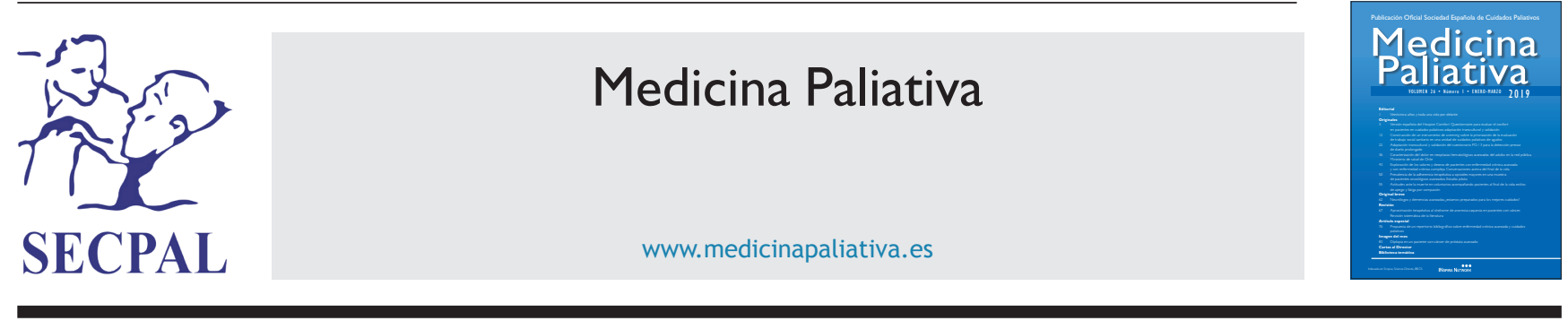

\title{
EDITORIAL
}

\section{Veinticinco años y toda una vida por delante}

En este 2019 que acabamos de comenzar se cumplen los 25 años de la revista Medicina Paliativa (Med Paliat). Durante este periodo de tiempo hemos compartido conocimiento, experiencias e inquietudes. Entre todos hemos conseguido que la revista se convierta en referente en el ámbito de los Cuidados Paliativos en lengua castellana.

Recientemente se ha publicado un estudio en el que se indica que Medicina Paliativa es la décima revista del mundo en número de artículos publicados en cuidados paliativos del siglo xx. Con el esfuerzo de todos, tanto de los que han colaborado enviando manuscritos, sus revisores, como de los que han dirigido la revista, hemos convertido a Medicina Paliativa en nuestra "joya de la corona". Por todo ello agradecemos el trabajo realizado a sus directores (Josep Porta, María Nabal y Miguel Ángel Cuervo), a sus subdirectores (a los mencionados añadir a Alberto Alonso), a todo el Comité Editorial (comité directivo, asesor, comité de expertos internacionales, comité editorial adjunto), a las diferentes juntas directivas de la SECPAL que han dado todo su apoyo a la revista, y a las editoriales Arán y Elsevier.

Consideramos que merece una mención especial la labor realizada por los revisores de los trabajos enviados para su publicación. Ha sido fundamental su colaboración durante todo este proceso. Gracias a su experiencia, trabajo incondicional y capacidad docente, han ido seleccionando los artículos más interesantes y mejor realizados, así como orientando a los autores de los mismos para mejorarlos y pulirlos todo lo posible.

Indudablemente sin autores, sin ideas de investigación y sin problemas que resolver y compartir, la revista estaría vacía. Juntos hemos conseguido que poco a poco la investigación en Cuidados Paliativos en España y en Latinoamérica se consolide cada vez más. Estamos haciendo que los Cuidados Paliativos ayuden a ensanchar la vida. No en vano, los autores españoles en Cuidados Paliativos estamos en el $7 .^{\circ}$ puesto de un ranking mundial sobre el factor de impacto de publicaciones en nuestro ámbito.

Por último, hay que agradecer a todos los pacientes y familiares que han participado en nuestras investigaciones, así como al apoyo de nuestros familiares, que han fundamentado la base de los estudios y reflexiones publicadas, como del trabajo editorial de fondo.

El año 2019 también es especial para Medicina Paliativa. Comenzamos un nuevo año y una nueva época de cambios para la revista. Circunstancias diversas han hecho que coincidan en el tiempo el cambio de editorial, el cambio de formato y el cambio de dirección de la revista. Se nos ha pedido a Alberto Alonso y a mí liderar este reto que afrontamos con ilusión, energía, nuevas ideas y, al mismo tiempo, responsabilidad y compromiso. Ilusión por continuar el legado de nuestros predecesores, energías y nuevas ideas para tirar adelante este gran proyecto, y responsabilidad por el encargo de seguir cuidando la revista.

Medicina Paliativa se enfrenta a varios retos en los años venideros. Uno de ellos es su viabilidad y sostenibilidad. La crisis ha hecho mella en todos los lugares y también ha afectado a la revista. Hay que tener en cuenta que casi la mitad del presupuesto de la SECPAL estaba destinado a la revista. La situación económica y la posibilidad de responder a nuevas necesidades han hecho que se decida cambiar de editorial (Inspira Network). Asimismo, y con criterios de sostenibilidad, se ha decidido desestimar el formato de la revista en papel y cambiar a un formato electrónico. También se están valorando nuevas vías de financiación.

Dentro del carácter social que tiene la revista, se ha planteado la necesidad de que la revista sea accesible al mayor número de profesionales sanitarios dedicados a los cuidados paliativos a nivel mundial. Para ello, se ha planteado que los números publicados de la revista sean de acceso abierto tras un periodo de un año de exclusividad para los socios. Asimismo, continuamos la labor iniciada con la dirección previa para conseguir que la revista sea órgano de expresión de otras sociedades, como la Asociación Latinoamericana de Cuidados Paliativos (ALCP), la Sociedad Española de Cuidados Paliativos Pediátricos (PEDPAL) o la Asociación Portuguesa de Cuidados Paliativos (APCP). 
Una de las mayores dificultades que tiene Medicina Paliativa es su visibilidad e impacto dentro de la revistas especializadas del ámbito. Se ha realizado un análisis bibliométrico de la revista, así como de presencia, en las principales bases bibliográficas por parte de Inspira Network, en el que muestra las oportunidades que tenemos de estar indexados en dichas bases de datos bibliográficas, así como de la obtención de certificados de calidad de revistas biomédicas. También se han detectado algunas áreas de mejora, como son el elevado número de publicaciones realizado por los propios miembros del comité editorial, así como el elevado número de estudios retrospectivos publicados, de menor calidad científica. Es un proceso de mejora a largo plazo pero que entre todos lo conseguiremos.

En esta nueva etapa de cambios para la revista apuntamos algunas de nuestras ideas y propósitos: 1) envío periódico del índice de contenidos de la revista a los socios; 2) promocionar mayor presencia en las redes sociales; 3 ) posibilidad de traducir algunos artículos a la lengua inglesa; 4) potenciar el carácter docente de la revista, creando periódicamente un artículo de formación que pueda servir de formación continuada certificada.

Para conseguir todos estos objetivos, es necesario tener un comité que sea ágil, comprometido, responsable y eficaz. De acuerdo con estas premisas y valores, estamos en pleno proceso de reestructuración del comité editorial y de las directrices a seguir. En este sentido, también se está realizando una revisión y actualización de revisores. Su trabajo y esfuerzo es primordial para el buen funcionamiento de la revista. La calidad de sus revisiones, así como los cumplimientos de los plazos de revisión, permiten que la revista alcance unos grados adecuados de calidad. En agradecimiento a este esfuerzo, y con el objetivo de fidelizar su compromiso, se están estudiando fórmulas para realizar formación específica en lectura crítica y proceso editorial, así como la obtención automatizada de certificados de colaboración.

Por último, es necesario el apoyo por parte de los socios y los lectores: el envío de trabajos para revisión, los comentarios, las críticas, las colaboraciones como revisores o la promoción de los artículos en las redes sociales son actuaciones que nos ayudarán a mejorar día a día la revista de todos. A todos os animo a participar de vuestra revista, para que esta tenga una sana y larga vida.

J. González-Barboteo

Director de Medicina Paliativa Institut Català d'Oncologia. Hospital Duran i Reynals. L'Hospitalet de Llobregat, Barcelona jgbarboteo@hotmail.com 